\title{
Determination of Organochlorine Pesticides in Some Vegetable Samples Using GC-MS
}

\author{
Cemile Ozcan \\ Department of Chemistry, Science and Art Faculty, Kirklareli University, \\ Kirklareli, Turkey
}

Received: 6 November 2015

Accepted: 26 January 2016

\begin{abstract}
This study investigated the level of pesticide pollution using marrow squash (Cucurbita pepo L.), cherry tomato (Solanum lycopersicum var. cerasiforme), banana pepper (Capsicum annuum), lettuce (Lactuca sativa L.), purslane (Portulaca oleracea L.), green beans (Phaseolus vulgaris L.), cucumber (Cucumis sativus L.), and onion (Allium flavum L.) in Kirklareli, Turkey. For this purpose, the concentrations of organochlorine pesticides were determined by gas chromatography-mass spectrometry (GC-MS). Vegetables were prepared for analysis by QuEChERS extraction method. Concentrations of Hexachlorocyclohexane $(\Sigma \mathrm{HCH})$, aldrin, heptachlor, dieldrin, endosulfan, methoxychlor and dichlorodiphenyltrichloroethane $\left(\sum D D T\right)$ were determined in vegetables collected from different points in Kirklareli. The LOD and LOQ were between $0.02-0.26$ and $0.06-0.87 \mu \mathrm{g} / \mathrm{L}$, respectively. The RSDs of the migration time ranged from $2.4 \%$ to $7.7 \%$ for the 18 analytes, indicating the good repeatability of the method. Recoveries of the spiked analytes in vegetables ranged from $83 \%$ to $104 \%$, respectively. The obtained concentrations for pesticides in all vegetables studied were in the range ND-73.6 $\mu \mathrm{g} / \mathrm{kg}$.
\end{abstract}

Keywords: organochlorine pesticides, QuEChERS, GC-MS, vegetables

\section{Introduction}

Kirklareli, one of the Black Sea provinces in northwestern Turkey, has a catchment area of $6,550 \mathrm{~km}^{2}$. The use of pesticides in agricultural areas can increase toxicity and pollution in the environment. Pesticides are potential chemical pollutants extensively used for agricultural purposes due to their low cost and high effectiveness. They may accumulate in living creatures as decomposition. Counted among the most important sources of pesticides, such as agricultural applications and industrial pollutants of soil, are inorganic and

*e-mail: cemilebal23@hotmail.com organic fertilizers, fungicides, liming, sewage sludge, and irrigation waters $[1,2]$.

The use of pesticides in agricultural areas can increase the levels of toxicity and pollution in an ecological environment. Pesticides are potential chemical pollutants extensively used for agricultural purposes due to their low cost and high effectiveness. They may, for instance, accumulate in living creatures during decomposition, which can cause degradation to the environment. The most prevalent sources of pesticide come from agricultural and industrial applications, thus polluting the soil. Among the culprits are inorganic and organic fertilizers, fungicides, lime, sewage sludge, and irrigation water [3]. About half of all chemicals (whether natural or synthetic) chronically 
tested in animal cancer tests at the maximum tolerated dose (MTD), were established as carcinogens [4].

Organochlorine pesticides in these vegetables may have accumulated in the environment in various ways such as through industry, fossil fuels, agriculture, and other human activities. The increasing agricultural and anthropogenic activities of humans has intensified the emissions of various pollutants into the environment, including toxic metals and pesticides [5]. Pollution by pesticides is a problem of increasing significance for ecological, evolutionary, nutritional, and human health [6-10]. Organochlorine pesticide compounds are known to create certain health problems such as cancer, immune system malfunction, and disruption of hormonal functions [11].

The extensively used and highly sensitive analytical techniques for determination and quantification of these pesticides at low concentrations in food samples are GCMS, HPLC-MS, HPLC-DAD, and GC-ECD [12-15]. They can provide compound confirmation and detailed information on the structure of the compound analyzed, such as seperation and detection. The function of GC-MS is identification, quantification, and analysis of a compound [16]. The most widely used extraction techniques for pesticides in plants are microwave extraction (MAE) [17], ultrasound extraction (UAE) [18-21], Soxhlet [22], supercritical fluid extraction [23], and accelerated solvent extraction [24].

The aim of this study is to determine the concentrations of organochlorine pesticides in marrow squash (Cucurbita pepo L.), cherry tomato (Solanum lycopersicum var. cerasiforme), banana pepper (Capsicum annuum), lettuce (Lactuca sativa L.), purslane (Portulaca oleracea L.), green beans (Phaseolus vulgaris L.), cucumber (Cucumis sativus L.), and onion (Allium flavum L.) in the province of Kirklareli (Turkey) by GC-MS (pesticides including $\sum \mathrm{BHC}\left(\alpha-\mathrm{BHC}, \beta-\mathrm{BHC}, \gamma\right.$-BHC, $\delta$-BHC), $\sum \mathrm{DDT}\left(4,4^{\prime}-\right.$ DDD, 4,4'-DDE, 4,4'-DDT), $\alpha$-Endosulfan, $\beta$-Endosulfan, Endosulfan sulfate, Heptachlor, Heptachlor-endo-epoxide, Aldrin, Dieldrin, Endrin aldehyde, Endrin ketone, Endrin, and Methoxychlor). Kirklareli is a location with intense industry and agriculture.

\section{Materials and Methods}

\section{Instrumentation}

The organochlorine pesticides were analyzed by GC-MS, using an Agilent 5975C MSD system and Agilent 7890A model in Kirklareli University. An HP-5 MS IU column ( $30 \mathrm{~m}$ x $250 \mu \mathrm{m}$ x $0.25 \mu \mathrm{m})$ was used with Helium as the carrier gas. Injector temperature, split flow, and injection volume were $250^{\circ} \mathrm{C}, 1 \mathrm{~mL} / \mathrm{min}$ and $1 \mu \mathrm{L}$. The GC oven temperature was kept constant at $110^{\circ} \mathrm{C}$ for 5 min to $320^{\circ} \mathrm{C}$ at a rate of $8^{\circ} \mathrm{C} / \mathrm{min}$. MS fragmentation voltage was taken at $70 \mathrm{eV}$. Component identification was carried out using spectrometric electronic libraries (NIST) [25].

\section{Standard and Reagents}

The standard stock solutions of organochlorine pesticide mix 2, 2,000 mg/L in toluene, (including $\sum \mathrm{BHC}$ $\left(\alpha\right.$-BHC, $\beta$-BHC, $\gamma$-BHC, $\delta$-BHC), $\sum$ DDT $\left(4,4^{\prime}-\mathrm{DDD}\right.$, 4,4'-DDE, 4,4'-DDT), $\alpha$-Endosulfan, $\beta$-Endosulfan, Endosulfan sulfate, Heptachlor, Heptachlor-endoepoxide, Aldrin, Dieldrin, Endrin aldehyde, Endrin ketone, Endrin and Methoxychlor) were purchased from Dr. Ehrenstorfer $\mathrm{GmbH}$ (a standard mixture solution containing 2,000 $\mathrm{ng} / \mu \mathrm{L}$, all 18). All solvents were HPLC-grade and other chemicals were analytical reagent grade. Double-distilled water (HPLC-grade, 18.2 ELGA) was used for all preparations.

Using 2,000 mg/L, stock was prepared using a mixture of $1 \mathrm{mg} / \mathrm{kg}(1000 \mu \mathrm{g} / \mathrm{L})$ intermediate stocks. The standard solutions were prepared from a dilution of their intermediate stock standard solutions at concentrations of $100,50,25,10,5$, and $1 \mu \mathrm{g} / \mathrm{L}$ in toluene. All solutions were stored in the dark at $4^{\circ} \mathrm{C}$. Working solutions were prepared by dilution of standard stock solution with toluene. Standard obtained through a purification system identification, quantification, and analysis of the compounds was done by GC-MS.

\section{Sample Preparation for Determination of Organochlorine Pesticides}

Marrow squash (Cucurbita pepo L.), cherry tomato (Solanum lycopersicum var. cerasiforme), banana pepper (Capsicum annuum), lettuce (Lactuca sativa L.), purslane (Portulaca oleracea L.), green beans (Phaseolus vulgaris L.), cucumber (Cucumis sativus L.) and onion (Allium flavum L.) were utilized as samples in this study. About $1,000 \mathrm{~g}$ of plants were collected from a public bazaar in Kirklareli. All samples were homogeneously mixed and put into dry plastic bags (washed with distilled water).

After homogenization of plant samples, approximately $5 \mathrm{~g}$ portions were added to $10 \mathrm{ml}$ dichloromethane in a $50 \mathrm{~mL}$ PTFE centrifuge tube. The sample was centrifuged in a $50 \mathrm{~mL}$ polypropylene centrifuge tube. Sodium acetate $1.5 \mathrm{~g}$ and anhydrous magnesium sulfate $6.0 \mathrm{~g}$ in supernatant were added to remove moisture and the compound was stirred for 3 min using the vortex. The sample was then centrifuged again at $5^{\circ} \mathrm{C}$ and $10 \mathrm{~min}$ at 7,000 rpm. The supernatant extraction was followed by a clean-up step using a solid-phase extraction with $400 \mathrm{mg}$ PSA, $1,200 \mathrm{mg} \mathrm{MgSO}_{4}$ (extracted using an SPE cartridge) [2628]. Pesticides in the sample extract were concentrated for dryness at $35^{\circ} \mathrm{C}$ using a gentle nitrogen stream. This was dissolved in $1 \mathrm{~mL}$ of hexane and filtered through a syringe filter of $0.45 \mu \mathrm{m}$. Afterward, the extracts $(1 \mu \mathrm{L}$ injection volume) were quantified by gas chromatograph with mass detector (GC-MS).

\section{Quantitation}

Linearity, precision, accuracy, limit of detection (LOD), limit of quantitation (LOQ), and recovery 
Table 1. The linear regression $(y=a x+b)$, correlation coefficients $\left(\mathrm{R}^{2}\right)$, LOD $\left(\mu \mathrm{g} \mathrm{L}^{-1}\right)$, LOQ $\left(\mu \mathrm{g} \mathrm{L}^{-1}\right), \mathrm{MRL}\left(\mu \mathrm{g} \mathrm{kg}{ }^{-1}\right)$ and $\% \mathrm{RSD}$ in pesticide standard solution range different levels and spiked recoveries and RSD of the method.

\begin{tabular}{|c|c|c|c|c|c|c|c|}
\hline Pesticide & $y=a x+b$ & $\mathrm{R}^{2}$ & LOD & LOQ & Recovery (\%) & MRL & $\%$ RSD \\
\hline$\alpha-\mathrm{HCH}$ & $1998,9 x-9625.8$ & 0.9944 & 0.13 & 0.43 & 85 & 10 & 7.2 \\
\hline$\beta-\mathrm{HCH}$ & $868,8 x-3487$ & 0.9949 & 0.26 & 0.87 & 83 & 10 & 6.1 \\
\hline$\gamma-\mathrm{HCH}$ & $803.77-3602.9$ & 0.9927 & 0.26 & 0.87 & 92 & 10 & 6.6 \\
\hline$\delta-\mathrm{HCH}$ & $1567.2 x-9449.6$ & 0.9925 & 0.02 & 0.06 & 85 & 10 & 5.1 \\
\hline Heptachlor & $983.7 x-5414.6$ & 0.9923 & 0.06 & 0.19 & 104 & 10 & 5.5 \\
\hline Heptachlor-endo-epoxide & $577.48 x-2803.9$ & 0.9943 & 0.18 & 0.60 & 96 & 10 & 4.4 \\
\hline Aldrin (HHDN) & $1541.9 x-6458$ & 0.9958 & 0.03 & 0.10 & 83 & 10 & 7.7 \\
\hline$\alpha$-Endosulfan & $492.08 x-2610.4$ & 0.9937 & 0.14 & 0.46 & 85 & 50 & 3.0 \\
\hline 4,4'-DDE & $4884.1 x-24947$ & 0.9932 & 0.03 & 0.10 & 83 & 50 & 3.1 \\
\hline 4,4'-DDD & $6000 x-50000$ & 0.9855 & 0.04 & 0.13 & 96 & 10 & 3.8 \\
\hline 4,4'-DDT & $3176.4 x-18901$ & 0.9978 & 0.03 & 0.10 & 94 & 10 & 2.4 \\
\hline Dieldrin & $1922.6 x-10689$ & 0.9932 & 0.12 & 0.40 & 88 & 50 & 4.0 \\
\hline Endrin & $247.79 x-856.09$ & 0.9955 & 0.12 & 0.40 & 85 & 50 & 6.9 \\
\hline$\beta$-Endosulfan & $581.31 x-2944.3$ & 0.9937 & 0.03 & 0.10 & 88 & 10 & 3.8 \\
\hline Endrin-aldheyde & $996.05 x-7104.4$ & 0.9901 & 0.06 & 0.21 & 92 & 50 & 4.9 \\
\hline Endosulfan-sulfate & $535.88 x-4463.1$ & 0.9885 & 0.08 & 0.27 & 86 & 10 & 7.1 \\
\hline Endrin-ketone & $815.84 x-5530.5$ & 0.9909 & 0.07 & 0.23 & 103 & 10 & 5.7 \\
\hline Methoxychlor & $3566.4 x-21247$ & 0.9964 & 0.06 & 0.20 & 101 & 5 & 4.1 \\
\hline
\end{tabular}

parameters were determined for the pesticides. An eightlevel 1-100 $\mu \mathrm{g} / \mathrm{L}$ calibration series was established with three analyses at each concentration level for determining linearity. The calibration curve was plotted automatically. LOD and LOQ had signal-to-noise ratios of 3 and 10, respectively [29].

Calibration graphs for pesticides were established in a range of $1-100 \mu \mathrm{g} / \mathrm{L}$ with correlation of coefficients from 0.9855 to 0.9978 for all analytes. The maximum residual limits (MRL) in foods of organochlorine pesticides, retention time (RT min), linear regression $(y=a x+b)$, correlation coefficients (R2), LODs, LOQs, and \%RSDs are shown in Table 1. Limits of detection ranged from 0.02 to $0.26 \mu \mathrm{g} / \mathrm{L}$ for organochlorine pesticides. Limits of quantification ranged from 0.06 to $0.87 \mu \mathrm{g} / \mathrm{L}$ for pesticides. The RSDs percentage of migration time ranged from 2.4 to 7.7 for the analytes, indicating good repeatability of the method. The procedure was checked for recovery efficiencies by analyzing uncontaminated vegetable samples spiked with organochlorine pesticide standard $(\mathrm{n}=5)$. The spike blanks, solvent blanks, and duplicate samples were analyzed in each of 10 samples. In addition, surrogate standard was added to each of the samples to monitor procedural performance and matrix effects. The recoveries of surrogate spiked in plant samples ranged from $83 \%$ to $104 \%$ (Table 1 ).

\section{Results and Conclusion}

In the article we studied the content of organochlorine pesticides in marrow squash (Cucurbita pepo L.), cherry tomato (Solanum lycopersicum var. cerasiforme), banana pepper (Capsicum annuum), lettuce (Lactuca sativa L.), purslane (Portulaca oleracea L.), green beans (Phaseolus vulgaris L.), cucumber (Cucumis sativus L.), and onion (Allium flavum L.). This could possibly have been the result of industrial pollution, as pesticides could easily have been absorbed into plant leaves from the air or soil. The presence of organochlorine pesticide residues in foods has been a problem for decades. Residues of organochlorine pesticides were found in all food samples analyzed. However, their concentrations were many times lower than the permissible limits in place in other countries. Organochlorine pesticides are resistant to degradation, which allows them to persist in the environment for a long time and become widespread via atmospheric and water transport mechanisms [30-32].

In this study, organochlorine pesticides in vegetables were determined and analyzed by GC-MS. The optimized conditions were found to be $1 \mathrm{ml} / \mathrm{min}$ for flow rate in the mobile phase, $1 \mu \mathrm{l}$ for injection volume, and $70 \mathrm{~V}$ for fragmentation potential. The optimized method was applied for the determination of organochlorine pesticide in vegetable samples. The results obtained for vegetables 
Table 2. Concentration of organohlorine pesticides detection in vegetables $\left(\mu \mathrm{g} \mathrm{kg}^{-1}\right)$.

\begin{tabular}{|c|c|c|c|c|c|c|c|c|}
\hline Pesticides & $\begin{array}{l}\text { Banana } \\
\text { pepper }\end{array}$ & $\begin{array}{c}\text { Marrow } \\
\text { squash }\end{array}$ & $\begin{array}{l}\text { Cherry } \\
\text { tomato }\end{array}$ & Lettuce & Onion & Purslane & $\begin{array}{l}\text { Green } \\
\text { beans }\end{array}$ & Cucumber \\
\hline$\alpha-\mathrm{HCH}$ & $4.80 \pm 0.09$ & $3.82 \pm 0.03$ & $1.31 \pm 0.01$ & $4.70 \pm 0.04$ & $3.84 \pm 0.01$ & $4.02 \pm 0.03$ & $3.11 \pm 0.02$ & $4.06 \pm 0.01$ \\
\hline$\beta-\mathrm{HCH}$ & ND & $4.36 \pm 0.07$ & $3.02 \pm 0.09$ & $5.55 \pm 0.05$ & ND* & $4.51 \pm 0.03$ & ND & $10.8 \pm 0.9$ \\
\hline$\gamma-\mathrm{HCH}$ & $4.91 \pm 0.11$ & $3.73 \pm 0.08$ & $1.30 \pm 0.01$ & $4.71 \pm 0.09$ & $3.84 \pm 0.02$ & $3.86 \pm 0.02$ & $3.89 \pm 0.09$ & $10.9 \pm 0.9$ \\
\hline$\delta$-HCH & $5.00 \pm 0.08$ & $3.90 \pm 0.07$ & $1.76 \pm 0.01$ & $4.89 \pm 0.05$ & $3.97 \pm 0.02$ & $4.00 \pm 0.09$ & $3.98 \pm 0.09$ & $4.25 \pm 0.02$ \\
\hline Heptachlor & $7.28 \pm 0.11$ & $7.05 \pm 0.13$ & $2.12 \pm 0.02$ & $6.21 \pm 0.08$ & $9.65 \pm 0.11$ & $10.2 \pm 0.5$ & $7.70 \pm 0.11$ & $10.7 \pm 0.8$ \\
\hline $\begin{array}{l}\text { Heptachlor-endo- } \\
\text { epoxide }\end{array}$ & $4.21 \pm 0.08$ & $3.29 \pm 0.09$ & $1.56 \pm 0.05$ & $4.12 \pm 0.04$ & $3.33 \pm 0.08$ & $3.35 \pm 0.04$ & $3.33 \pm 0.03$ & $21.2 \pm 1.1$ \\
\hline Aldrin (HHDN) & $4.70 \pm 0.06$ & $3.84 \pm 0.08$ & $1.29 \pm 0.02$ & $4.45 \pm 0.03$ & $4.18 \pm 0.03$ & $4.16 \pm 0.06$ & $3.82 \pm 0.03$ & $14.2 \pm 1.1$ \\
\hline$\alpha$-Endosulfan & ND & ND & ND & ND & ND & ND & ND & $9.25 \pm 0.11$ \\
\hline 4,4'-DDE & $4.50 \pm 0.09$ & $3.63 \pm 0.03$ & $1.22 \pm 0.09$ & $4.50 \pm 0.03$ & $3.83 \pm 0.03$ & $3.69 \pm 0.04$ & $3.81 \pm 0.05$ & $4.09 \pm 0.11$ \\
\hline 4,4'-DDD & $32.7 \pm 1.3$ & $59.9 \pm 3.4$ & $11.8 \pm 0.9$ & $18.6 \pm 1.1$ & $36.4 \pm 2.2$ & $70.2 \pm 5.4$ & $32.1 \pm 1.9$ & $73.6 \pm 5.7$ \\
\hline 4,4'-DDT & $5.45 \pm 0.09$ & $7.10 \pm 0.17$ & $1.64 \pm 0.03$ & $7.45 \pm 0.09$ & $5.89 \pm 0.08$ & $7.49 \pm 0.11$ & $5.14 \pm 0.05$ & $5.10 \pm 0.05$ \\
\hline Dieldrin & $5.08 \pm 0.11$ & $5.36 \pm 0.09$ & $6.29 \pm 0.08$ & $5.15 \pm 0.08$ & $5.02 \pm 0.05$ & $6.76 \pm 0.09$ & $4.93 \pm 0.09$ & $4.48 \pm 0.08$ \\
\hline Endrin & $5.53 \pm 0.15$ & $4.35 \pm 0.11$ & $3.52 \pm 0.03$ & $5.47 \pm 0.06$ & $4.46 \pm 0.05$ & $4.56 \pm 0.04$ & $4.48 \pm 0.03$ & $4.55 \pm 0.04$ \\
\hline$\beta$-Endosulfan & $6.63 \pm 0.11$ & $5.36 \pm 0.09$ & $1.70 \pm 0.02$ & ND & $5.51 \pm 0.03$ & $6.78 \pm 0.04$ & $4.41 \pm 0.05$ & ND \\
\hline Endrin-aldheyde & $6.10 \pm 0.18$ & $5.25 \pm 0.14$ & $1.74 \pm 0.02$ & $6.03 \pm 0.09$ & $4.95 \pm 0.08$ & $5.49 \pm 0.05$ & $5.65 \pm 0.05$ & $5.34 \pm 0.08$ \\
\hline Endosulfan-sulfate & $7.58 \pm 0.09$ & $5.24 \pm 0.07$ & $1.79 \pm 0.01$ & $6.53 \pm 0.06$ & $5.33 \pm 0.05$ & $5.41 \pm 0.02$ & $5.67 \pm 0.05$ & $5.57 \pm 0.02$ \\
\hline Endrin-ketone & $5.60 \pm 0.11$ & $4.49 \pm 0.09$ & $1.58 \pm 0.02$ & $5.36 \pm 0.06$ & $4.78 \pm 0.04$ & $4.79 \pm 0.05$ & $4.51 \pm 0.06$ & $4.62 \pm 0.04$ \\
\hline Methoxychlor & $6.47 \pm 0.04$ & $5.72 \pm 0.04$ & $1.98 \pm 0.01$ & $7.22 \pm 0.05$ & $5.87 \pm 0.05$ & $5.86 \pm 0.01$ & $4.64 \pm 0.01$ & $5.91 \pm 0.02$ \\
\hline
\end{tabular}

$* \mathrm{ND}=$ not detected

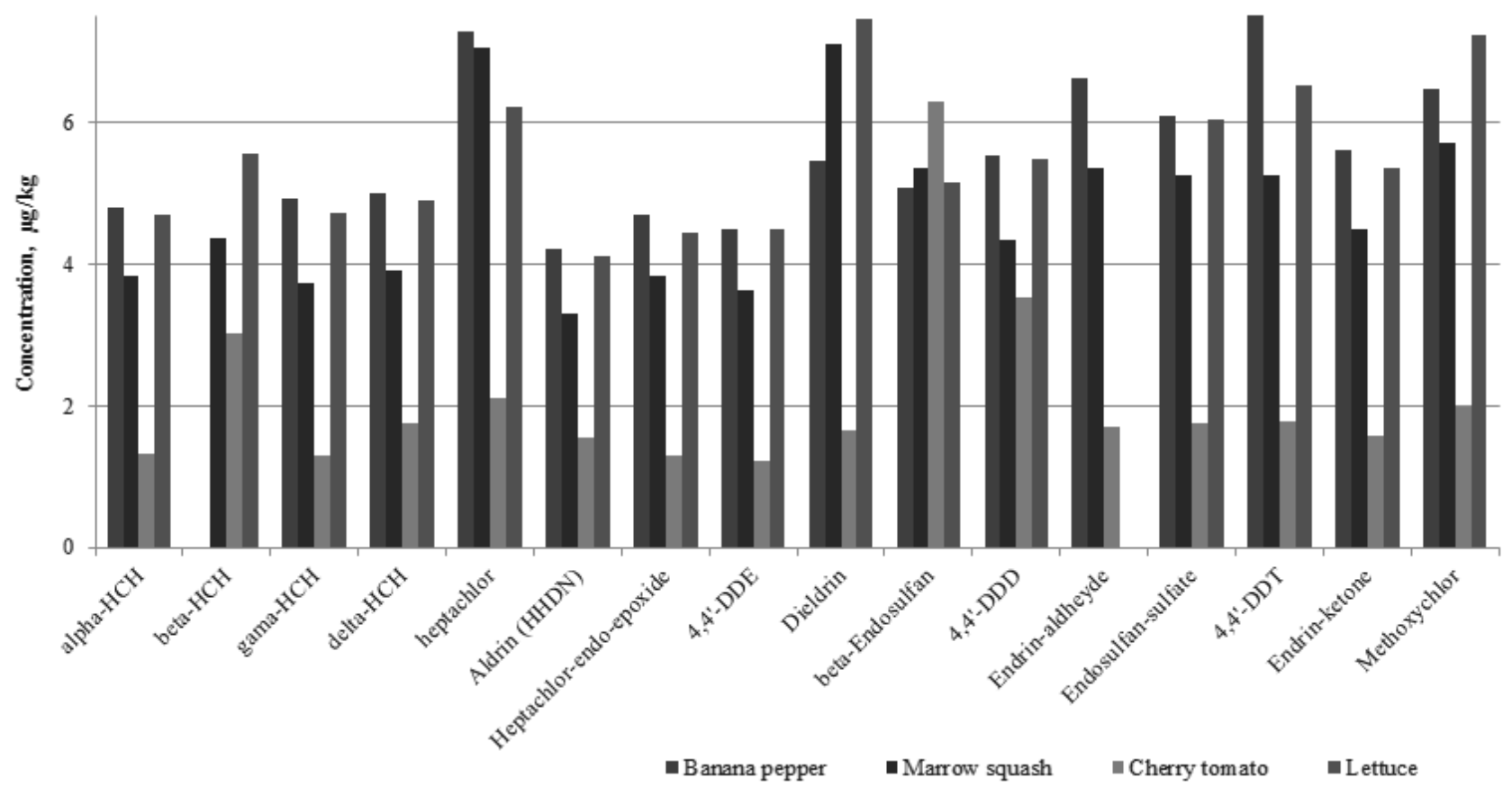

Fig. 1. Concentration graph of organochlorine pesticides in banana pepper, marrow squash, cherry tomato, lettuce. 


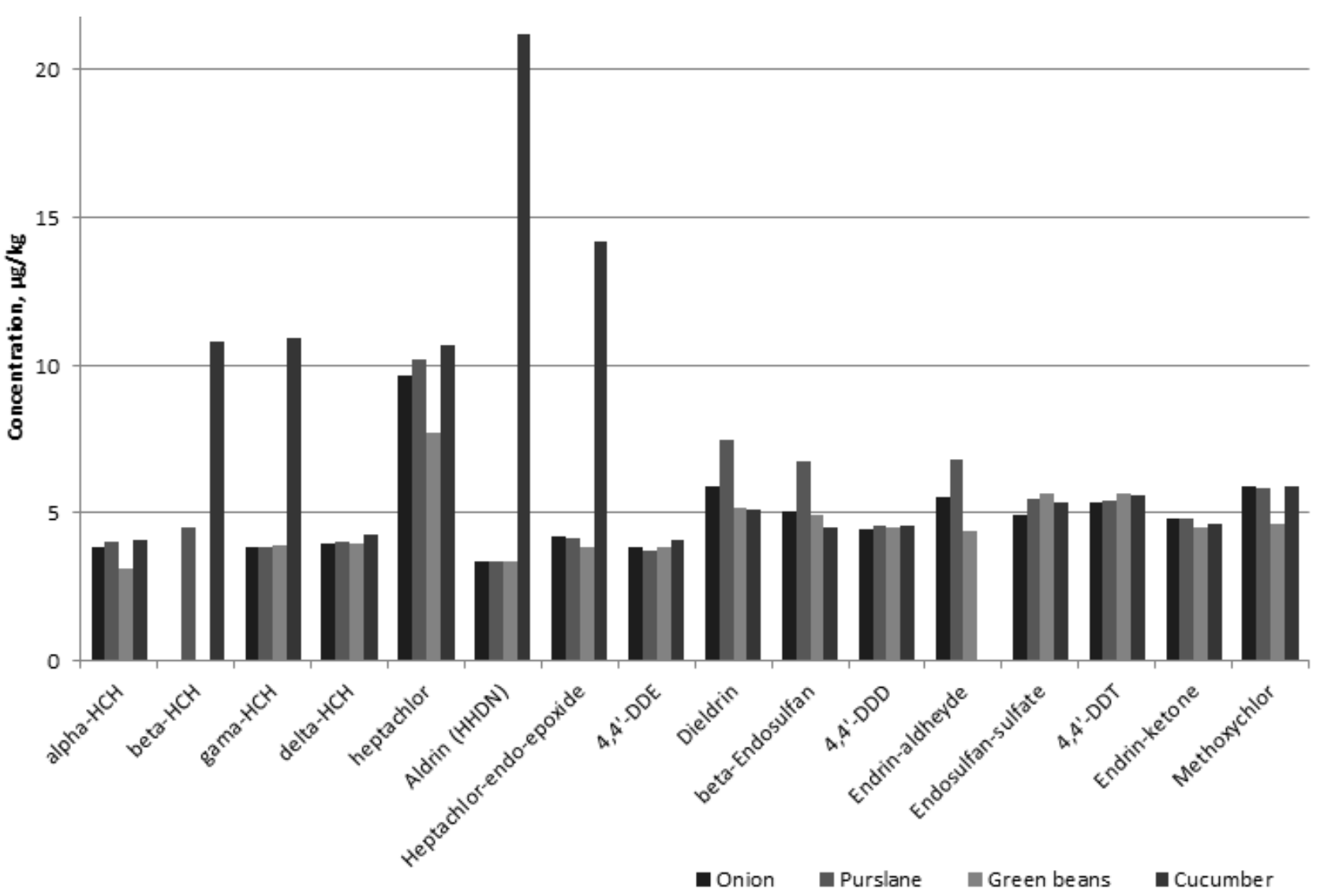

Fig. 2. Concentration graph of organochlorine pesticides in onion, purslane, green beans, cucumber.

are summarized in Table 2 and Fig. 1. The target pesticides were analyzed with good reproducibility and low detection limits using gas chromatography-mass spectrometry with electron impact ionization-possitive mode (GC-MSEI (+)). After elution-cleaning with SPE cartridge for pesticides in vegetables we developed a simultaneous method for analysis by GC-MS. The main advantage of this method is that extraction and clean-up are performed in less time with a low volume of solvent. Additionally, the proposed method is a sensitive, reproducible, and reliable alternative to the normally used methods; moreover, it is inexpensive, easy, and rapid (QuEChERS method). This study demonstrated that the method using QuEChERS and GC-MS is very effective in analyzing the organochlorine pesticides in the vegetable samples.

The concentrations of $\alpha-\mathrm{HCH}, \beta-\mathrm{HCH}, \gamma-\mathrm{HCH}$, $\delta$-HCH, Heptachlor, Aldrin (HHDN), Heptachlor-endoepoxide, $\alpha$-Endosulfan, 4,4'-DDE, Endrin, Dieldrin, $\beta$-Endosulfan, 4,4'-DDD, Endrin-aldheyde, Endosulfan sulfate, 4,4' DDT, Endrin-ketone, and Methoxychlor in vegetable samples were found among 1.31 to $4.80 \mu \mathrm{g} / \mathrm{kg}$, $\mathrm{ND}$ to $10.8 \mu \mathrm{g} / \mathrm{kg}, 1.30$ to $10.8 \mu \mathrm{g} / \mathrm{kg}, 1.76$ to $5.00 \mu \mathrm{g} / \mathrm{kg}$, 2.12 to $10.7 \mu \mathrm{g} / \mathrm{kg}, 1.56$ to $21.2 \mu \mathrm{g} / \mathrm{kg}, 1.29$ to $14.2 \mu \mathrm{g} / \mathrm{kg}$, $\mathrm{ND}$ to $9.25 \mu \mathrm{g} / \mathrm{kg}, 1.22$ to $4.50 \mu \mathrm{g} / \mathrm{kg}, 11.8$ to $73.6 \mu \mathrm{g} / \mathrm{kg}$, 1.64 to $7.49 \mu \mathrm{g} / \mathrm{kg}, 4.48$ to $6.76 \mu \mathrm{g} / \mathrm{kg}, 3.52$ to $5.53 \mu \mathrm{g} / \mathrm{kg}$, $\mathrm{ND}$ to $6.78 \mu \mathrm{g} / \mathrm{kg}, 1.74$ to $6.10 \mu \mathrm{g} / \mathrm{kg}, 1.79$ to $7.58 \mu \mathrm{g} / \mathrm{kg}$, 1.58 to $5.60 \mu \mathrm{g} / \mathrm{kg}$ and 1.98 to $7.22 \mu \mathrm{g} / \mathrm{kg}$, respectively (Table 2 and Figs 1-2).
Concentrations of $\alpha$-Endosulfan were not determined in vegetable samples except for cucumber $(9.25 \mu \mathrm{g} / \mathrm{kg})$. In addition, the amount of $\alpha-\mathrm{HCH}, \beta-\mathrm{BHC}$, Heptachlor, Aldrin, Heptachlor-endo-epoxide, Endrin, and Methoxychlor in cucumber were determined over the MRL border value. The concentrations of Endrin in all samples were found 1.2 to 7.4 times greater than the MRL value. Therefore, over MRL value of Heptachlor we found 1.02 to 1.07 times greater in purslane and cucumber, respectively. The amount of Endrin-aldheyde was not determined in lettuce and cucumber. The concentrations of organochlorine pesticides in cherry tomato were found below the MRL values, except for endrin. Eventually, this could have been the result of industrial pollution, as pesticides could have been easily absorbed translocated in plant leaves from air or soil. But it may have been also a result of eating the leaves of animals. In addition, the relative abundances of individual percentage graph of organochlorine pesticides in vegetables are shown in Fig. 3.

Organochlorine pesticides are of global concern because of their widespread occurrence, bioaccumulation, persistence, and toxicity. So for the improment of the world and food safety, sources of pollution should be identified and eliminated. Such information is valuable to health care professionals, researchers, and food manufacturers in preparing nutritious products. Levels of organochlorine pesticides in some products may also be 


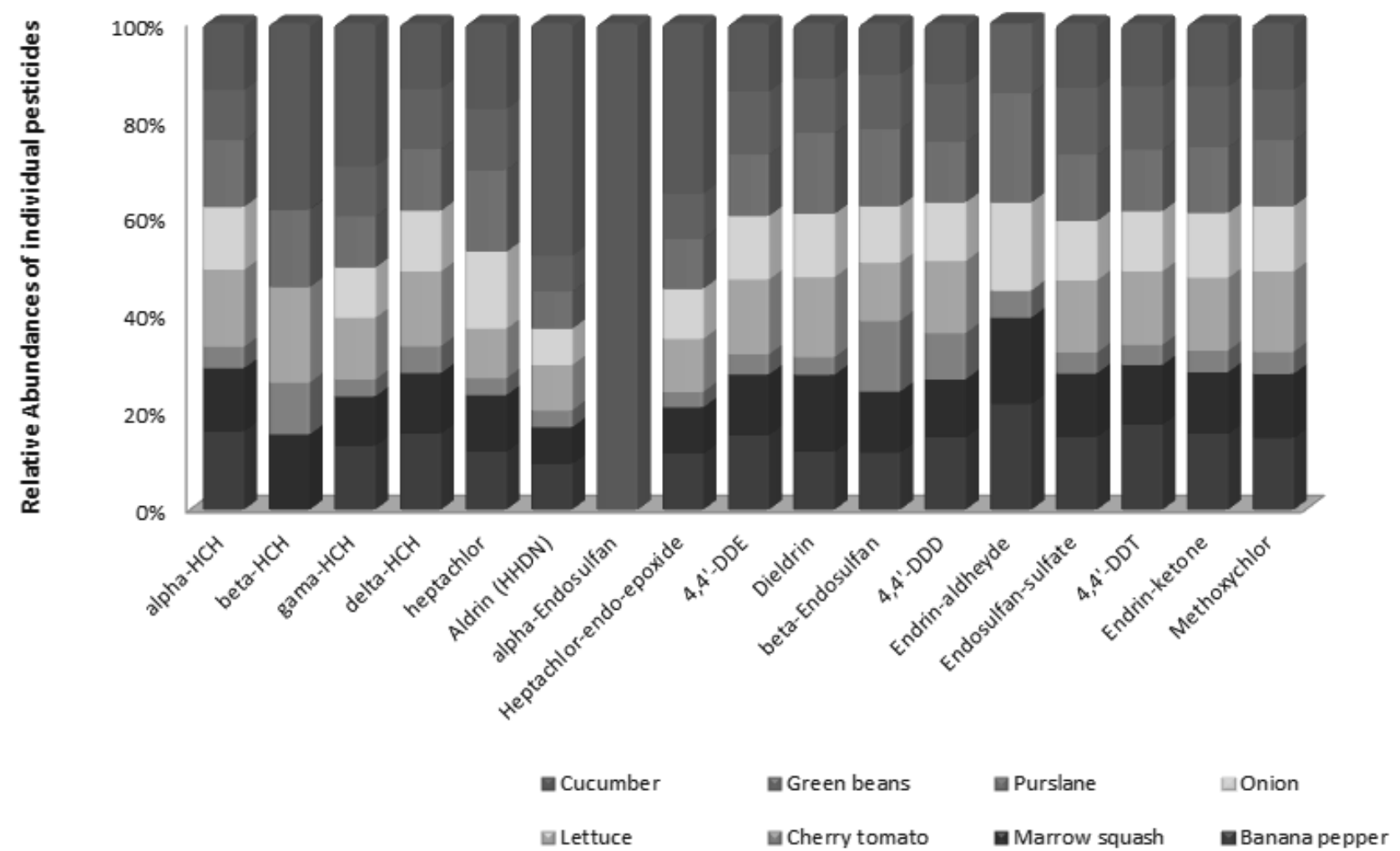

Fig. 3. The relative abundances of individual percentages graph of organochlorine pesticides in vegetables.

unexpected and hence informative and may lead to further analysis and research. Most farmers in Turkey rely on their own experience and on pesticide sellers to help them select the appropriate pesticide. Overall, these findings provide insight into the habits of pesticide use during vegetable cultivation by Kirklareli farmers. Most do not rely on advertisements, extension officers, or government agencies for guidelines on proper pesticide use. While levels have declined in recent years in many countries, a number of these chemicals (called persistent organic pollutants), persist in our environment.

Therefore, a multi-residue method has been developed and successfully validated for the rapid detection of 18 pesticide residues of the same chemical classes in vegetable samples by GC-MS. The high pesticide levels in some of the samples suggest that these pesticides are being used indiscriminately. This could cause considerable health problems - not only to the public but also to farmers. Therefore, training and information on pesticide use and their residues might be established. This research is required to further elucidate the pollution sources of organochlorine pesticides in the region. In addition, more studies on accumulation of organochlorine pesticides are required to accomplish a comprehensive ecological risk assessment.

\section{References}

1. OLIVER M.A. Soil and human health: a review. European journal of Soil Science. 48, 573, 1997.
2. FAIRBROTHER A., WENSTEL R., SAPPINGTON K., WOOD W. Framework for metals risk assessment. Ecotoxicol. Environ. Saf. 68, 145, 2007.

3. EL-SHAHAWI M.S., HAMZA A., BASHAMMAKH A.S., AL-SAGGAF W.T. An overview on the accumulation, distribution, transformations, toxicity and analytical methods for the monitoring of persistent organic pollutants. Talanta. 80, 1587, 2010.

4. AMES B.N., PROFET M., SWIRSKY L. Gold, Dietary pesticides (99.99\% all natural). Proc. Nad. Acad. Sci. USA 87, 7777, October 1990 Medical Sciences.

5. AKTAR W., SENGUPTA D., CHOWDHURY A. Impact of pesticides use in agriculture: their benefits and hazards. Interdiscip. Toxicol. 2, 1-12, 2009.

6. FRENICH A.G., VIDAL J.L.M., SICILIA A.D.C., RODRIGUEZ M.J.G., BOLANOS P.P. Multi residue analysis of organochlorine and organophosphorus pesticides in muscle of chicken, pork and lamb by gas chromatographytriple quadrupole mass spectrometry. Anal. Chim. Acta. 558, 42-52, 2006.

7. BEARD J., MARSHALL S., JONG K., NEWTON R., TRIPLETT-MCBRIDE T., HUMPHRIES B., BRONKS R. 1,1-trichloro-2,2-bis (p-chlorophenyl) ethane (DDT) and reduced bone mineral density. Arch. Environ. Health. 55, 177, 2000.

8. SMEDS A., SAUKKO P. Identification and quantification of polychlorinated biphenyls and some endocrine disrupting pesticides in human adipose tissue from Finland. Chemosphere. 44 (6), 1463, 2001.

9. BORGA K., GABRIELSEN G.W., SKAARE J.U. Biomagnification of organochlorines along a Barents Sea food chain. Environ. Pollut. 113 (2), 187, 2004.

10. KRAUTHACKER B., ROMANIĆ S.H., REINER E. Polychlorinated Biphenyls and Organochlorine Pesticides in Vegetation Samples Collected in Croatia. Bull. Environ. 
Contam. Toxicol. 66 (3), 334, 2001.

11. BARRIADA-PEREIRA M., GONZALEZ-CASTRO M.J., MUNIATEGUI-LORENZO S., LOPEZ-MAHIA P., PRADA-RODRIGUEZ D., FERNANDEZ-FERNANDEZ E. Organochlorine pesticides accumulation and degradation products in vegetation samples of a contaminated area in Galicia (NW Spain). Chemosphere. 58 (11), 1571, 2005.

12. CLEMENT R.E., YANG P.W., KOESTER C.J. Environmental analysis. Anal. Chem. 73 (12), 2761, 2001.

13. OZCAN C., DILGIN Y., YAMAN M. Determination of Quercetin in Medicinal Plants Such as Rose Hip (Rosa canina), Bettle (Urtica dioica), Terebinth (Terebinthina chica) and Purslane (Portulace oleracea) using HPLC-MS Method. Asian J. Chem. 24 (8), 3396-3400, 2012.

14. OZCAN C., YAMAN M. Determination of Kaempferol in Rosa canina, Urtica Dioica, Terebinthina Chica and Portulace Oleracea by HPLC-MS. Asian J. Chem. 25 (17), 9758-9762, 2013.

15. OZCAN C., YAMAN M. Determination of Myricetin in Medicinal Plants by High-Performance Liquid Chromatography. Instrumen. Sci. Technol. 43 (1), 44, 2015.

16. CHOWDHURY M.T.I., RAZZAQUE M.A., KHAN M.S.I. Chlorinated pesticide residue status in tomato, potato and carrot. J Exp. Sci. 2 (1), 1-5, 2011.

17. PASTOR A., VAZQUEZ E., CISCAR R., DE LA GUARDIA M. Efficiency of the microwave-assisted extraction of hydrocarbons and pesticides from sediments. Anal. Chim. Acta. 344 (3), 241, 1997.

18. LINO C.M., DA SILVEIRA M.I.N. Extraction and clean-up methods for the determination of organochlorine pesticide residues in medicinal plants. J Chromatograp A. 769 (2), 275-283, 1997.

19. DOONG R.A., LEE C.Y. Determination of organochlorine pesticide residues in foods using solid-phase extraction clean-up cartridges. Analyst. 124 (9), 1284, 1999.

20. OZCAN S., TOR A., AYDIN M.E. Application of ultrasoundassisted emulsification-microextraction for the analysis of organochlorine pesticides in waters. Water Research. 43 (17), 4269, 2009.

21. ROMANIK G., GILGENAST E., PRZYJAZNY A., KAMINSKI M. Techniques of preparing plant material for chromatographic separation and analysis. J. Biochem. Biophys. Meth. 70 (2), 253, 2007.

22. PAN J., XIA X.X., LIANG J. Analysis of pesticide multiresidues in leafy vegetables by ultrasonic solvent extraction and liquid chromatography-tandem mass spectrometry. Ultrasonics Sonochemistry. 15 (1), 25, 2008.
23. GONÇALVES C., CARVALHO J.J., AZENHA M.A., ALPENDURADA M.F. Optimization of supercritical fluid extraction of pesticide residues in soil by means of central composite design and analysis by gas chromatographytandem mass spectrometry. J Chromatograp. A. 1110 (1-2), 6, 2006.

24. LEHOTAY S.J., ELLER K.I. Development of a method of analysis for 46 pesticides in fruits and vegetables by supercritical fluid extraction and gas chromatography/ion trap mass spectrometry. J. AOAC Int. 78 (3), 821, 1995.

25. OZCAN C. Pollution evaluation of organochlorine pesticides and heavy metals from cheese samples in Kirklareli, Turkey. J Food, Agriculture \& Environ. 13 (2), 70, 2015.

26. U.S.E.P.A: Method 3535a solid-phase extraction (SPE). Ohio: USEPA, 2007.

27. AHLBORG U.G., LIPWORTH L., TITUS-ERNSTOFF L., HSIEH C.C., HANBERG A., BARON J., TRICHOPOULOS D., ADAMI H.A. Organochlorine compounds in relation to breast cancer, endometrial cancer, and endometriosis: an assessment of the biological and epidemiological evidence. Crit. Rev. Toxicol. 25 (6), 463, 1995.

28. STEFANELLI P., SANTILIO A., CATALDI L., DOMMARCO R. Multiresidue analysis of organochlorine and pyrethroid pesticides in ground beef meat by gas chromatographymass spectrometry. J Environ. Sci. Health Part B. 44 (4), 350, 2009.

29. SHRIVASTAVA A., GUPTA V.B. Methods for the determination of limit of detection and limit of quantitation of the analytical methods. Chronicles of Young Scientists. 2 (1), 21, 2011.

30. ATTIA S., GRISSA K.L., LOGNAY G., BITUME E., HANCE T., MAILLEUX A.C. A review of the major biological approaches to control the worldwide pest Tetranychus urticae (Acari: Tetranychidae) with special reference to natural pesticides: Biological approaches to control Tetranychus urticae. J Pest Sci. 86 (3), 361, 2013.

31. PANG G.F., LIU Y.M., FAN C.L., ZHANG J.J., CAO Y.Z., LI X.M., LI Z.Y., WU Y.P., GUO T.T. Simultaneous determination of 405 pesticide residues in grain by accelerated solvent extraction then gas chromatographymass spectrometry or liquid chromatography-tandem mass spectrometry. Anal. Bioanal. Chem. 384 (6), 1366, 2006.

32. KORYTAR D., LEONARDS P., BORE J., BRIKMOAN U. High-resolution separation of polychlorinated biphenyls by comprehensive two-dimensional gas chromatography. J. Chromatogr. A. 958 (1-2), 203, 2002. 